\title{
Exploratory Study of 3 Cases of Corporate Crisis and Stock Market Reaction
}

\author{
Morten Spanner \\ Webster University \\ Geoffrey VanderPal \\ Webster University
}

The topic of overreaction, and reactions in the stock-market is highly important to understand for anybody with a financial background, or with a general interest in the stock-market. To this extend it seemed as authors would agree that overreactions in the stock-market is a common concept, however there is a great deal of uncertainty about how, and when it would happen. Therefore, this paper will have a quantitative exploratory case-study approach, with the purpose of providing more insights in how the market reacts to certain situations. It was chosen to use legitimacy as the criteria for the crisis events, meaning all the cases presented in the paper will have experienced legitimacy issues in relations to the crisis. A theoretical framework will be used for the analysis that highlights some of the important aspects from the crisis situations, which will in the end be used for a combined comparison.

What was found in this paper was that the level of uncertainty information and uncertainty risk that a crisis created could play a significant role when it comes to reactions from the market. It was seen that the importance of having a proper response strategy to legitimacy crisis situations was fairly minimal. The case-studies showed that the company who seemed to have the worst response to the event, was also the company that experienced the least impact from the crisis, in terms of stock-market reaction.

\section{LITERATURE REVIEW}

In the literature, there has been focus on two theories, being 'overreaction theory' and 'legitimacy theory'. The main results from these theories will be discussed shortly, to summarize the most important aspects of the literature reviewed.

The first that was discussed was the overreaction theory of De Bondt \& Thaler (1985) as well as Conrad \& Kaul's (1993) revision of De Bondt \& Thaler's (1985) work. What was originally found by De Bondt \& Thaler (1985), was that they found a strong indicator that the market overreacted because they put too much value on 'winning stocks', and underestimated 'losing stocks' too much. This would cause the 'winning stocks' to have an inflated value, and the 'losing stocks' to be valued too low, in general. Conrad \& Kaul (1993) questioned the findings made by De Bondt \& Thaler (1985), and claimed that 
much of what was originally described as an overreaction was actually due to seasonality, more specifically the 'January effect', thereby voiding the findings.

Next the paper looked at the work of Brown et al,. (1988) and Corrado \& Jordan (1997), and gave an in-depth discussion on the 'Uncertainty Information Hypothesis' (UIH). This UIH should be seen as an extension to the well-known 'Efficient Market Hypothesis'. The 'Efficient Market Hypothesis' is a hypothesis suggesting that the market is 'always in balance', meaning over- or underreaction is nonexisting, because a stock-value is always a clear reflection of the actual value of the stock, because it will reflect all available information, thereby correct the stock-price accordingly. The UIH, is simply considering both available and unavailable information, meaning the more information is unknown, the riskier the stock, and thereby the lower the stock-price. What Brown et al., (1988) then argues is that investors will tend to not take all available and unavailable information into account, so when a large amount of uncertainty information arrives, the market will in general show an overreaction. They explain this by saying that investors are in general risk averse, so in a case like this, many would sellout, with the intent to minimize a potential loss.

The discussion of the works by Choi \& Hui (2014), they describe that they believe the most important when determining the reaction from the stock-market, is the level of surprise an event has. This means that the more unanticipated an event is, the higher the risk of an overreaction from the market. Furthermore, they describe that an underreaction would typically occur if the event is anticipated. They analyzed this by looking to the football betting market before a match. They would pick a match with a big underdog and a huge favorite, then look at the reaction from the market after the first goal was scored. Here they found that they would typically experience an overreaction when the underdog scored the first goal, and an underreaction, should the favorite team net the first goal.

Finally, in terms of overreaction, there was a look at the work of Piccoli et. al., (2017), who also discuss the importance of the surprise factor. They describe that the more an event contradicts one's previous beliefs, the higher the chance of an overreaction. This is due to people believing too strongly in what they have previously believed to be true, so when they have to rethink their beliefs, they will tend to put too much importance to the new information - again causing an overreaction. They also describe the importance of multiple events, and how this can change the outcome of a crisis/event completely. They describe that when an initial event is followed by another that is related to it, three things can happen. Either a 'reversal', a 'momentum' or a 'mixed'. What this means, is that the next event could cause the trend of the stock-price to reverse, thereby causing the stock-price to go the opposite direction, gain momentum, and thereby increase direction of the stock-price, or a mix of both.

After this, the paper had a look at mainly two papers concerning legitimacy. However, these theories were supported by other authors as well. First of all, the paper gave a general understanding of the term 'legitimacy' in a corporate context by looking at the classic article from Suchman (1995). He describes how norms, values and beliefs have become the core of any modern organization, and these can be highly important aspects when looking at how other people's perception of the company is. He further describes how the level of support can be an important aspect to understand for the company, because this will often determine how much legitimacy the company requires to function. When seeking active support for the company, the company would require much more legitimacy than it would if only seeking passive support for the company. He also describes how companies can see legitimacy as a tangible asset, that can sometimes be traded for the option to act a little illegitimate. Finally, the paper looked at how Suchman (1995) described the 'three stages of legitimacy'. This is the description of how any company would find themselves in either of these categories, being gaining legitimacy, maintaining legitimacy or repairing legitimacy. Because of the nature of the paper, understanding how to gain legitimacy in the first place is not too important, so the focus turned to maintaining and repairing legitimacy. He argues that maintaining legitimacy is by far the easiest task for any company, because people would not start to question legitimacy without a reason, however repairing it can be quite a challenge, and getting to this step should be avoided at all costs.

Finally, the paper looked at the journal of Massey (2001). This was a look at how a company should react or prepare for a legitimacy crisis. The main focus of this was Massey's (2001) description of the 
'Crisis Management Plan' (CMP) and how this can be of huge help to a company in a legitimacy crisis scenario. He describes that the company should always stick to one strategy, keep the information flow high, and always show action. As for strategies, he describes that the company can: "(a) deny the problem, (b) provide an excuse for why the problem occurred, (c) justify the problem, or (d) explain the reasons why the problem occurred' (Massey, 2001, p. 158).

\section{METHODOLOGY}

Many authors have, during the past decades, tried to find patterns in the way investors over- or underreact to certain events, but with mixed success, which have left room for wondering if there are other reasons for people to over- or underreact in comparison to what have previously been studied. This was the original thought process that led to the research questions and the foundation for this paper. There were multiple ways to 'attack' and address questions like this, therefore the paper required careful considerations before even setting out to write the first paragraph. Before anything else could happen, one need to get a broad understanding of the topic 'overreaction', itself, and figure out what exactly have been previously researched, so the paper can successfully build upon that and create new original content, instead of simply repeating previous research. While researching, it became increasingly evident that many authors agreed that overactions in the stock-market is a common phenomenon, but as just mentioned, the reason is often blurry, and to find a distinct pattern is even more difficult. In the following sections the different parts of the paper will be dissected and discussed in depth, answering the questions of how and why, but first a short discussion concerning the research questions.

What was specifically chosen for this paper was a 'Qualitative Exploratory Case-Study' approach, for a few distinguished reasons. As have been mentioned, a broad range of recognized authors have been studying the specific topic of overreactions in the stock-market, but a big issue remains. Most of the people who have studied the topic are not in agreement on a whole range of ideas, and many contradict one another. Therefore, simply picking some random variables for a quantitative approach would not be very helpful, given that this would be completely haphazard (Yin, 2003). Therefore, the only logical choice, if one wants to study this field, would be to first do an exploratory study to figure out what aspects might be influential for the reactions in the stock-market in a crisis event, and then considering if a quantitative research method would be desirable (Yin, 2003). To this extend, Marczyk, De Matteo, \& Festinger (2005) argues that the case-study approach can be highly beneficial to bring up new research ideas in cases like these, which have great complexity to them.

Since the paper will be utilizing a case study approach, it is important to choose the right number of cases to provide a productive result. As Yin (2003) describes, if one chooses to only go with one casestudy it can be highly risky because that would mean putting "all your eggs in one basket" (Yin, 2003, $p$. 53), which could, in a worst-case scenario, lead to a useless paper, should that case-study be faulty or simply not a good representation of this kind of event. Therefore, the obvious choice was to settle on a multiple case-study approach, but then the question rose on, how many would be sufficient? According to Yin (2003), in some cases two could be sufficient, but the more would often be the better - the restriction for almost any study is time and resources. To this extend, he describes that it can further strengthen the results of the case studies, if the chosen case studies are having a contrast between them. Hence, this paper will go with three case studies. However, some similarities should be evident between the cases, thus legitimacy was included as one variable, for the mere reason that this seemed an important theory that no other author has focused on in relations to overreactions in the stock-market. Because no one have been focusing on this, it is highly interesting and could yield some very interesting results. As mentioned, besides being legitimacy crisis situations, these cases have also been picked because they are very different in nature. This was a criteria, when picking the cases, because according to Yin (2003), deliberately picking cases that provide "contrasting situations" (Yin, 2003, p. 54) can give a more reliable case study.

Because the paper is doing a qualitative exploratory approach the goal is to provide a much greater understanding of a few specific crisis situations, possibly overreaction situations, which can help mold a 
hypothesis for further research. This means that the way the paper will be structured is to set up this casestudy approach with three different cases being the Volkswagen emission scandal from 2015, the Wells Fargo account crisis from 2016 and the United Airlines incidence from 2017, which have the one thing in common that all experienced a similar crisis. This will mean that it is highly important to define what is a 'similar crisis' as well as establishing the reasoning behind picking these specific cases. In this paper, they need to be crisis situations that can be identified as a legitimacy crisis according to the theory. In general, this is a way to distinguish different crisis situations from one another and focus on one specific aspect. The reason that 'legitimacy' was chosen as that distinguisher has been briefly touched upon and is that it is a highly interesting theory because it often seems to create a very different crisis than a regular crisis situation, meaning there might be clear similarities in the way investors react to such a crisis.

It should be noted that all three cases did not happen in the same market given that this was not a criteria that the author of this paper deemed crucial, but this can be considered a limitation for the outcome of the analysis.

\section{Theoretical Framework}

First, one should figure out if the market has overreacted. This will be done in a straight forward fashion, meaning it will be by measuring the stock-price from the day before the crisis stroke and 90-days into the future. This 90-day window will be enough to give an understanding about how the market reacted to that specific crisis, and not too long, so that other factors will mislead the information at hand, unless some other big news broke in that period. The market growth or decline will also have to be considered, meaning should there be a growth in the overall market by $5 \%$ during this 90 -day window, that will have to be subtracted so that it only has the company's development displayed. The overreaction theory will then need to be applied to get a broader understanding of what happened during the crisis, with the regards to the previous finding by Corrado \& Jordan, (1997), Brown, et al., (1988), Choi \& Hui, 2014, and Piccoli et al. (2017). This means that there will be a discussion on the level of uncertainty information and how the risk for the stakeholders has increased by the event, so that it can be discussed, if the reaction is justified or not. This will further be debated with the focus on how well the managers and the company managed to minimize the uncertainty risk created by the crisis, by looking at how fast they reacted, how much information they provided and what information they provided, and if this will reflect in the stock-price. Then we will look at the level of surprise that the event had, meaning the more surprising the event, the higher the chance for an overreaction from the stock-market, according to the theory.

After determining the reaction or overreaction, one will look at the legitimacy aspect of the crisis, and if the overreaction can be explained with the legitimacy problems. Here, important factors will again be the level of surprise. In relations to legitimacy, it will be discussed if something like this has happened before, and what the audiences' previous perception of the company was. Then it will be discussed if the company had a clear CMP or not and how they applied it. This is probably impossible to completely answer without being in the company, but that is not important for this study. The reason being that the paper is only interested in the way the company responded. For example, how quickly and efficient the company responded. This should give us an idea about if the company had a plan and if it worked. Here it is important to look at their strategy, if they chose to deny the crisis, excuse themselves by blaming, justify the events, or simply explain what happened and hope for forgiveness.

After analyzing each case, the final step will be to compare the crises and the development of the different crises situations and look for similarities, that could point us in the direction of a tendency. One will have to keep in mind that the sample size is obviously too small to explain how strong the correlation is between overreactions and the legitimacy crisis; however, the hope is to display that it is very likely to be a tendency.

To narrow this down to a more specific model, the following aspects should be considered and discussed in the analysis of each of the different cases. The following bullet point model will be a summary of what have just been discussed and will then go into the following model: 


\section{Reaction}

- Did the stock-market over- or underreact 90-days into the future?

- Is it initially a slow reaction from the market or a 'shock reaction'?

- Has the level of uncertainty information/risk changed, and how?

- Was this event a surprise, or have it been a long time underway?

- Did the event stand-alone (stand-alone factor) or did multiple events happen after the initial crisis?

\section{Legitimacy}

- Do they use Strategic, Institutional or a mix of both?

- How fast did the company react to the crisis and did they show to have prepared a CMP?

- Can the legitimacy issues be argued to be caused by cultural or in other ways geographical differences (apply if the company works internationally)?

- Is this type of crisis an usual occurrence or have the company's legitimacy been questioned before (this is in relations to the level of surprise in the reaction as well). In other words, do they have any 'goodwill'?

The following model is how it would look when used in an analysis:

TABLE 1

\section{SUMMARY OF "COMPANY NAME"}

\begin{tabular}{ll}
\hline Level of Uncertainty & Moderate to Low: \\
information/risk & Explanation. \\
Type of Crisis & Legitimacy: \\
& Explanation. \\
Level of Surprise & Moderate: \\
& Explanation. \\
How (fast) did the & Small and slow reaction: \\
market react? & Explanation. \\
CMP Prepared? & No: \\
& Explanation. \\
Multiple events? & No: \\
& Explanation. \\
Over- or Underreaction? & Small to non-overreaction: \\
& Explanation. \\
\hline
\end{tabular}

Table 1: Example of Framework

It is obviously not sufficient to simply create the different categories, and then make an educated guess of why, for example, Level of Surprise is 'moderate'. The reason for this is that it would be terribly difficult to consistently recreate, because it would rely on the individual's general assumptions and perception. Because this is a case-study, there will, nonetheless, be reliant on the analyst, meaning the outcome of the analysis can change depending on who is analyzing it. This can be seen as a limitation, but also a necessity when taking an exploratory case-study approach because, giving the analyst some leeway, will allow for new hypothesis to emerge (Yin, 2003). However, it is definitely important to have a good way of measuring in a case study, this is something that both Marczyk, et al., (2005) and Yin (2003), discuss to an extent, even though the data used is non-metric, the idea is to quantify it to some degree. Therefore, the following will be a brief discussion on each category, meaning why this was selected for the model, and how it would be desirable to measure each of them. The limitations of the model will also be discussed to an extent. 


\section{Level of Uncertainty Information/Risk}

Here the analyst will look to the stock-market to determine the 'level of uncertainty information/risk'. This is the theory provided by Brown et al., (1988) and Corrado \& Jordan (1997), and is concerned with how much uncertainty information and risk the crisis provided the stakeholders. If there is a large amount of uncertainty information/risk, this would suggest an overreaction in the market. In this category, the analyst can choose 5 categories, being 'low', 'low to moderate', 'moderate', 'moderate to high' and 'high'. The goal here is to provide an understanding of how the shareholders perceived the crisis and this can be done in two ways, however, neither Brown et al., (1988) or Corrado \& Jordan (1997) provide a way to analyze how much uncertainty information/risk a crisis has created. In this theoretical framework, the determining factor will be a combination of two. One will simply look at the reaction in the stockmarket and use that as the explanation for how much uncertainty information/risk the crisis created. This will be the first determining factor. The following would be how much the stock should change during the first 5 days to fit into each category. 'Low': $0 \%$ up to $2.5 \%$, 'low to moderate': $2.5 \%$ up to $5 \%$, 'moderate': $5 \%$ up to $7.5 \%$, 'moderate to high': $7.5 \%$ up to $10 \%$, 'high' $10+\%$. Second, should be the analyst's own perception, meaning the analyst will have to look at what have happened to the company, that is still now known, such as, do they have a standing lawsuit that can be costly, do they risk losing a large portion of their sales, etc. This should be combined with the change in stock-price and the analyst will then have to explain why a specific category was chosen.

\section{Type of Crisis}

In this category, there are two options that will have to be determined - financial or non-financial crisis and legitimacy or non-legitimacy crisis. Given that one crucial criteria for picking a case to be analyzed, is that it must be a legitimacy crisis, one would expect to always categorize the crisis as at least a 'legitimacy crisis'. Should this not be the case, and it is in-fact a non-legitimacy crisis, the analyst will have to abandon the case, given that it would not be following one of the essential criteria. The way that one will determine whether the crisis is a financial crisis or a non-financial crisis, there are a few criteria to look at. For it to be a financial crisis, there must be a significant direct financial consequence for the company. If there is not, it cannot be described as a financial crisis. For example, in this paper, United Airlines did not face any direct financial consequences, only speculation. They would most likely face a lawsuit and there might be a potential customer loss, but this does not categorize as direct financial consequences. Where Volkswagen did experience a direct financial consequence, being the cars, they had to take back.

The word 'significant' suggest that one will also rely on the analyst's judgement, because it is not specified exactly how 'big' the consequence should be, which according to Yin (2003) is also acceptable in a case-study, however this is a point that could possibly benefit from being further narrowed down, and a limitation of the current theoretical framework.

\section{Level of Surprise}

The level of surprise is highly important for the study and the theoretical framework, as was seen in both Choi \& Hui (2014) and Piccoli et al., (2017). The level of surprise can help explain the reaction from the market. When using the framework, the level of surprise should be determined on a scale from small, moderate or high. To find these categories the analyst must use a combination of stock-price reaction in the market and general understanding of the crisis and the companies themselves. First determining factors is the change in stock-price. If the stock-price changed between $0 \%$ up to $3 \%$ within the first 7 days of the crisis it should be categorized as 'small'. If it changed 3\% up to $15 \%$ within the 7 days, it should be categorized as 'moderate' and if it changed more than $15 \%$ within the 7 days, it should be categorized as a 'high'. This will be the same factors used in the next category. Second is looking to each company and their history, as well as their field of operation, to determine if this could be considered a surprise or not. It should be seen as an addition to the stock-price, not the main tool of determining if the 
reaction is a surprise or not. The analyst must account for the reasoning behind the choice given that there is not a clear description of how to match the two outcomes. This is again a limitation of the theoretical framework, because the interpretation and understanding of the individual analyst can change the outcome.

This is related to the next category 'how fast did the market react', but needs its own category because this allows the analyst to describe and understand the crisis better.

\section{How (Fast) Did the Market React?}

As just mentioned, this should be seen as an extension of the previous category, level of surprise, further elaborating on the surprise factor, but solely focusing on how fast the market reacted to the event. This is again to provide a further understanding of how the crisis unfolded, but will provide valuable inside in if the market was shocked by this event or not, which is important when considering the theories of Choi \& Hui (2014) and Piccoli et al., (2017). The three categories in this event is, 'no reaction', 'slow and steady', or 'shock reaction'. These can be categorized by looking at the stock-price. If the stock-price changed between $0 \%$ up to $3 \%$ within the first 7 days of the crisis it should be categorized as 'no reaction'. If it changed 3\% up to $15 \%$ within the 7 days, it should be categorized as 'slow and steady' and if it changed more than $15 \%$ within the 7 days, it should be categorized as a 'shock reaction'. When a category is fairly close to being in between two, the analyst should describe it.

\section{CMP Prepared?}

The CMP prepared is an important factor of the model, provided by the work of Massey (2001). The point of bringing this into the model, is that it can provide the inside of how the company reacted in terms of legitimacy and legitimacy management, and because it can help give an understanding, if the preparation of such plan can help the company. There is usually no clear way of determining whether a company had a clear CMP or not, therefore this is one category that will rely on the analyst to some extent, because the analyst will have to use his/her own judgement. Here the options are simply 'Yes' or 'No' when answering in the theoretical framework. What the analyst will have to look for to determine whether the company had a CMP prepared is the way they handled the crisis. For example, did the company have a clear strategy from the very beginning of the crisis, did they change that strategy at some point, did they take and show actions, and how did well did they keep stakeholders informed of what is going on in the company.

\section{Multiple Events?}

The 'multiple events' is also an important aspect to consider when creating the framework, because this can change the crisis completely, as described by Piccoli et al., (2017). As have been described in the theory, the first thing to analyze is the stand-alone factor - meaning whether more than one event happened or not, in relations to the crisis. If no more than the one event happened, the analyst should simply put in a 'No' and would not need much further explanation. In this case, this category is fairly unimportant because this will not contribute very much to the study. On the other hand, should there be multiple events one will have to describe and understand these, by determining whether the observed result was a 'reversal', a 'momentum' or a 'mixed' reaction from the market.

This point of this category is not to be quantified, but need to be considered because it has been known to change the reaction of the market completely, should it happen (Piccoli et al., 2017).

\section{Over- or Underreaction?}

Once again, here the determining factor is the stock-market. The analysist will have to look to the initial reaction from the market, which should be the stock-price change within the first 10-days. Then look at the stock-price when the market has stabilized, which will be the period after 60-days to 90-days. Should something happen with the stock-price that is unrelated to the crisis, which was observed in the 
United Airline's case of this paper, the analyst must describe this to give the reader an understanding of this, but it should not affect the outcome which is how the analyst describes the reaction.

The analyst should categorize the event as either 'overreaction', 'underreaction', or non-over/underreaction. Furthermore, the author can choose to describe the reaction in the 'explanation', with 'small', 'moderate' or 'large', but this is purely to add value to the understanding of the crisis, and is not crucial to the initial judgement. The reason for this is that it is more difficult to specifically explain that for example, this is a big overreaction simply by looking at the stock-price change. This is also a point where the model can be expanded upon, to add even more value to it, and to the universalizing of the analysis.

\section{DATA REVIEW}

The data review will contain the three different cases, Volkswagen, Wells Fargo and United Airlines. For each company, there will be a short description about the crisis that they faced, based on information found on various large acknowledged news sources from around the world, including Forbes, New York Times, BBC etc.

\section{Volkswagen Crisis}

The emission crisis of Volkswagen officially started at the 18 of September 2015 because at this date, the Volkswagen Group were told to recall a total number of 482,000 cars sold in the United States, because "EPA (U.S. Environmental Protection Agency) issues a public notice of violation of the Clean Air Act" (Reuters, 2017). The reason for this, was that a whole range of Volkswagen's diesel cars were advertised and sold as highly clean and environmental friendly, but the cars showed highly different levels of emission depending on the circumstances. If the tests were done under regular test circumstances the car would show much less emission compared to if the car was tested outside under real world circumstances. The reason for this was that the software in the car were programmed to be able to detect whether the car was running under test circumstances or in the real world. This meant that the software in the car would turn on the emission control during the test, and off in the real world, causing the car to exceed the allowed emission for diesel cars in the United States by up to forty times - obviously produce vastly different results (Neate, 2015). When this was brought to the world's attention the bad publicity was bad enough in itself, but because the cars did not hold up to the minimum requirements of the Clean Air Act in the United States, the Volkswagen Group had to recall the previous mentioned cars (Reuters, 2017). This made the crisis even worse for Volkswagen because this made the crisis highly costly beside the bad publicity. Initially, they thought they could solve the issue at hand by simply updating the software in the cars, given that it was a software issue, not a hardware issue (Kollewe, 2015). This would make the car measure the correct emission number, but again - it would not hold up to the requirements and therefore were not an option. 


\section{FIGURE 1 \\ CHANGE IN STOCK-PRICE VW (\%)}

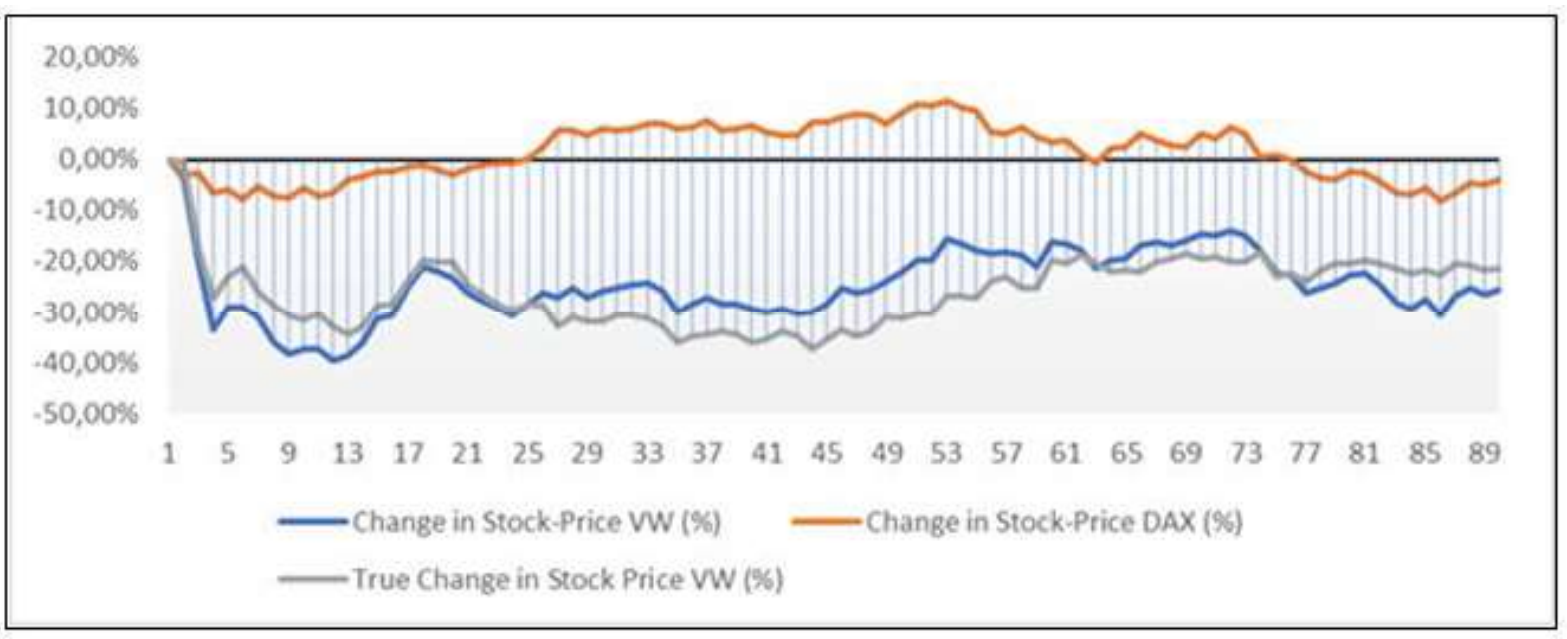

The real crisis has this fairly clear starting point, however there were some leading up to the crisis, as with many other crisis situations which will briefly be discussed. It can be argued that the whole issue started back in 2005, when Volkswagen set out to create a more environmental friendly diesel engine, known as the EA 189, with the goal of meeting the much stricter pollution standards of the United States regarding diesel engines. As it turned out, a big part of this plan was to create the software to make it possible, by cheating the emission tests (Reuters, 2017). The first real sign of the crisis emerged in May 2014, when "The California Air Resources Board (CARB) receives a study published by the International Council on Clean Transportation (ICCT) which shows NOx values for VW diesel vehicles deviate significantly between bench testing and road operation" (Reuter, 2017). However, this does not spark any major actions from any of the parties, but it leads to Volkswagen offering to recalibrate the cars in December 2014, which means that, at this point in time, Volkswagen were aware of the possible problems (Reuters, 2017). In the summer of 2015 Volkswagen established a taskforce of engineers to solve the ever-coming issue of Volkswagen produced vehicles showing wrong emissions, but at this point it was too late given that only a short while later, the real crisis broke as have already been discussed (Reuters, 2017).

It is worth noting that, according to Neate (2015) "the maximum fine for violations of the act is $\$ 37,500$ per vehicle, which works out to a maximum possible fine as high as \$18bn". This obviously posed a real threat to the investors of Volkswagen Group, because this could mean that the stock-price would drop even further, and can help to explain this extreme drop in stock-price. As we turn our attention towards the stock development displayed in Graph 1, after the crisis struck, one will notice a huge dip in the stock-price, dropping down $-27.13 \%$ in only four days from one day before the crisis struck (true change). The following days, we do not see any major swings in the stock-price, but 12 days into the crisis we can notice the lowest point in the initial drop, with a stock-price going all the way down to $-34.54 \%$ in comparison to the initial price. After that we see a swing back in Volkswagens favor, going back to $-19.81 \% 17$ days into the crisis. Despite this, it was followed by a downwards trend once again, going all the way down to $-37.36 \%$ after 43 days, producing the lowest point in the crisis. After this, we see the stock-price bouncing back and seems to stabilize between $-18 \%$ and $-22 \%$ compared to before the crisis. All these numbers can be examined in appendix 3.

So how did Volkswagen react to the crisis? The first reaction from Volkswagen came at the $20^{\text {th }}$ of September, meaning two days after the crisis broke, where the CEO of Volkswagen, Martin Winterkorn, says that Volkswagen are "deeply sorry that we have broken the trust of our customers and the public" (Wattles, 2015) following up with "We do not and will not tolerate violations of any kind of our internal rules or of the law" (Wattles, 2015). This can be argued to be a fairly late reaction from Volkswagen, 
however, they immediately took responsibility of the crisis, and wanted to show corporation (Rushe, 2015). The crisis was so severe that even the German counselor, Angela Merkel, called for more transparency in the German car giant, because it even posed a threat to the German market in general according to the counselor (Wattles, 2015). To this extend, Volkswagen sought this transparency by immediately ordering an external investigation of the cars and the software giving full access, thereby showing that this was a mistake, that they want to fix (Rushe, 2015). Initially, in the memo send out by the CEO, Martin Winterkorn, he said that he would not resign, however, at the $23^{\text {rd }}$ of September, he did in fact resign from the CEO position at Volkswagen, giving room for a 'fresh start' even though he continuously claimed that he "had no knowledge of the manipulation of emissions data." (Ewing, 2015). All this happened after a long meeting with the senior managers and the largest shareholder at Volkswagen (Ewing, 2015).

As a last point, at November $22^{\text {nd }}, 2016$, Volkswagen said that they will stop selling diesel vehicles in the United States (Forbes, 2017).

\section{Wells Fargo Crisis}

To describe the crisis that struck Wells Fargo, it would be logical to start by telling when the crisis started, but that is trickier than initially presumed. For the case of Wells Fargo, there are multiple options for picking a starting point of the crisis because this crisis unfolded over a very long period of time, as previously mentioned. One could argue that it started back in December 2013 where the Los Angeles Times initially accuses Wells Fargo for acting highly unethical by opening false checking-, savings- and credit cards accounts (Dwyer, 2017). In the article from Los Angeles Times (Reckard, 2013), they base their arguments on former employees, describing the practice of Wells Fargo as pure pressure to keep up to their quotas on sales. One employee describes it as: "If we did not make the sales quotas ... we had to stay for what felt like after-school detention, or report to a call session on Saturdays" (Reckard, 2013). In the accusation, there are multiple examples from all over the nation describing a similar story - the general mistreatment of the company employees and especially the customers. Many of the examples are with employees even acting desperately to meet the sales quotas set by the company, forcing them to act in a highly unethical way. However, from a crisis perspective, at this point in time, it is still accusations from former employees and not that many tangible facts which is therefore not the point in time where the crisis really kicked off. The starting point of the crisis could also be in May 2015, where a lawsuit was filed by a Los Angeles City attorney, Mike Feuer. That lawsuit was initially sparked by the investigations made by Los Angeles Times and their groundbreaking article about Wells Fargo back in 2013 (Dwyer, 2017). This could also be a starting point of the crisis, but at this point it is still accusations and could easily just be an attorney that sees a small opportunity in something farfetched. Therefore, the time selected as the starting point of the crisis is September 8, 2016- because this is the day of which Wells Fargo agrees to settle the lawsuit, and pay 185 million USD to regulators and 5 million USD in refunds to customers of the bank (Dwyer, 2017). This is the time of which Wells Fargo publicly accept that they are in fact guilty of the accusations at hand, and therefore the logical starting point of the official crisis.

The following graph is a graphical demonstration of the stock-market's reaction to the crisis, that can be found in appendix 6 : 


\section{FIGURE 2}

\section{CHANGE IN STOCK-PRICE WELLS FARGO (\%)}

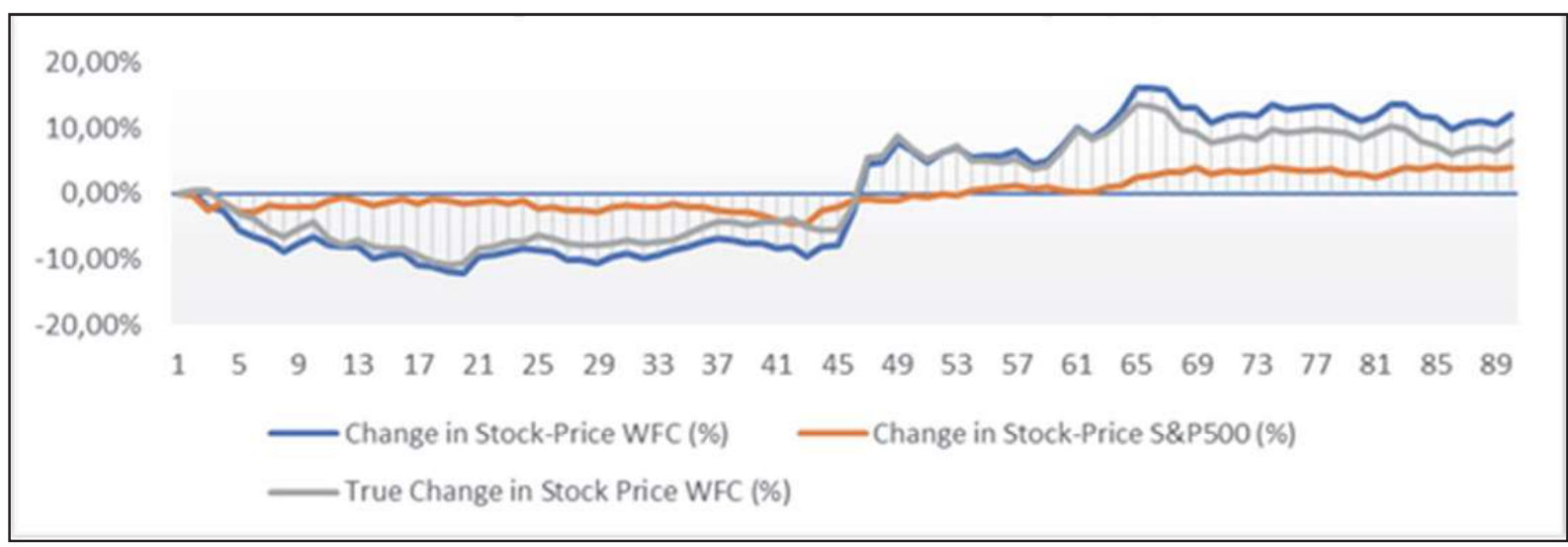

In the graph, the blue line reflecting the percent change in the stock-value of Wells Fargo, the orange line that reflect the percent change in the S\&P500 and lastly the grey line that reflect the true change in percent to the Wells Fargo stock when the 'market's reaction' is subtracted, as described in the method, and was also seen in the Volkswagen case. It will be the true change that is in focus, but all numbers can be examined in appendix 6. As can be seen in graph 2, after the crisis struck Wells Fargo at September 8, 2016, the stock-price took a fairly severe bump downwards. To highlight a few points of interest, 7 workdays after the announcement was made, the stock had already dropped by $-6.57 \%$. 14 workdays into the crisis, the stock-price was still dropping, and was now down to $-8.20 \%$. After 18 workdays, the stock hit its lowest point in the crisis, as it was down $-10.79 \%$. From that point though, the stock-price started to slowly regain territory and climb back up. The next major event we see in the stock-price is between the $44^{\text {th }}$ workday until the $48^{\text {th }}$ workday where the stock rises from $-5.61 \%$ to positive $8.83 \%$ compared to before the crisis. From this point on, we only see positive numbers, swinging from $3.79 \%$ to $13.52 \%$ in comparison to before the crisis struck.

So how did Wells Fargo react to this crisis? On September 8, the date of which the lawsuit was settled, Wells Fargo acted immediately by emailing a memo out to all its employees, for them and the world to see, which briefly described what had happened and what actions Wells Fargo were to take (Egan, 2016). They described how they regret what have happened, and how they want to take responsibility and action when mistakes like this occur. This can be seen in these two examples taken from the official memo: "We regret and take responsibility for any instances where customers may have received a product that they did not request" (Wells Fargo, 2016) and "At Wells Fargo, when we make mistakes, we are open about it, we take responsibility, and we take action" (Wells Fargo, 2016). Because this has come out the day of the settlement, it can easily be described as Wells Fargo being very fast in their reaction, which is typically good to keep the crisis under control according to the theory. The day after the crisis 'officially' broke, CNN brought a report that described how Wells Fargo have confirmed to CNNMoney, that the bank "had fired 5,300 employees over the last few years related to the shady behavior" (Egan, 2016), and have described that they will now "intently focused' on restoring customers' trust" (Egan, 2016). As part of the whole 'cleaning up the company by dismissing people', CEO, John Stumpf were also 'let go' (resigned) in the aftermath of the crisis, at October $12^{\text {th }}$ (Egan, 2016). From Wells Fargo's perspective, this is showing that they are indeed taking actions to stop this crisis. During the first month, Wells Fargo further promised that it would now stop their 'sales incentive program' by the start of 2017, which would help stop the excessive sales of extra financial products that customers do not need, and especially the products that they do not know about (Cowley, 2016).

In late-august, 2017, CNN brought yet another article about Wells Fargo and "their broken sales culture" (Egan, 2017), and in this article, they describe that even though Wells Fargo claimed to have 
taken responsibility and actions to fix their internal issues, almost a year after the settlement, they have still not managed to close that chapter completely (Egan, 2017).

\section{United Airlines Crisis}

When discussing legitimacy crisis situations, there have often been a lead up to the crisis, in one way or the other, but this crisis is different in that regard. What would be observed in previous discussed cases, is that it seems as the companies knew that something was wrong, and that indicators had come up before the crisis struck, that something could happen. In the case of United Airlines, it was very different. At the $9^{\text {th }}$ of April, a man named David Dao was violently dragged out of the United Airlines Express Flight 3411 which was going from Chicago to Louisville (Pignataro, 2017). The man was removed from the plane by the aviation police officials after he refused to give up his seat (Lartey, 2017). The whole episode was due to United Airlines overbooking their flights, and in the last minute before the flight was scheduled to takeoff, the crew requested that four seats needed to be cleared to make room for United Airlines personal. This extra personal was needed in another airport for their upcoming shift. It is fairly common practice among the aviation companies in the United States to overbook flights to maximize profit, but the problem in this case was that none of the passengers volunteered to give up the seat, in return of compensation (Lartey, 2017). This resulted in four passengers on the plane was randomly selected and were to leave the aircraft to make room for the previously mentioned United Airlines personal. Three of the selected people did leave the plane, but Dr. David Dao refused, because he argued that he needed to get back to the hospital where he worked, to take his shift, and it was therefore impossible. According to a fellow passenger onboard the aircraft, Dr. David Dao said "I'm not getting off the plane. I'm a doctor; I have to see patients in the morning" (Victor \& Stevens, 2017) when the flight personal told him the get off the aircraft. This 'forced' the personal on the flight to call for the aviation police. As the police arrived, Dr. David Dao continuously refused to get off the plane causing the officials to use force. This gave the passenger bruises and head injuries that resulted in him going to the hospital in Chicago (Creswell \& Maheshwari, 2017). Fellow passengers recorded the whole episode, and it is evident that the officials were acting highly aggressive towards the passenger, and it can be see how the passenger is dragged from the plane with a bloody face. Alongside that "Other passengers can be heard screaming and shouting 'Oh my God' and 'Look at what you did to him'," (Lartey, 2017). This video immediately hit social media, and almost instantaneously caused a PR nightmare for United Airlines (Creswell \& Maheshwari, 2017).

So how did the UAL stock react to this episode? What can be seen in the following graph 3 is the stock-price development for United Airlines, during the following 90 days of the crisis. The numbers that will be discussed in relations to the graph can be found in appendix 9: 


\section{FIGURE 3 \\ CHANGE IN STOCK-PRICE UNITED AIRLINES (\%)}

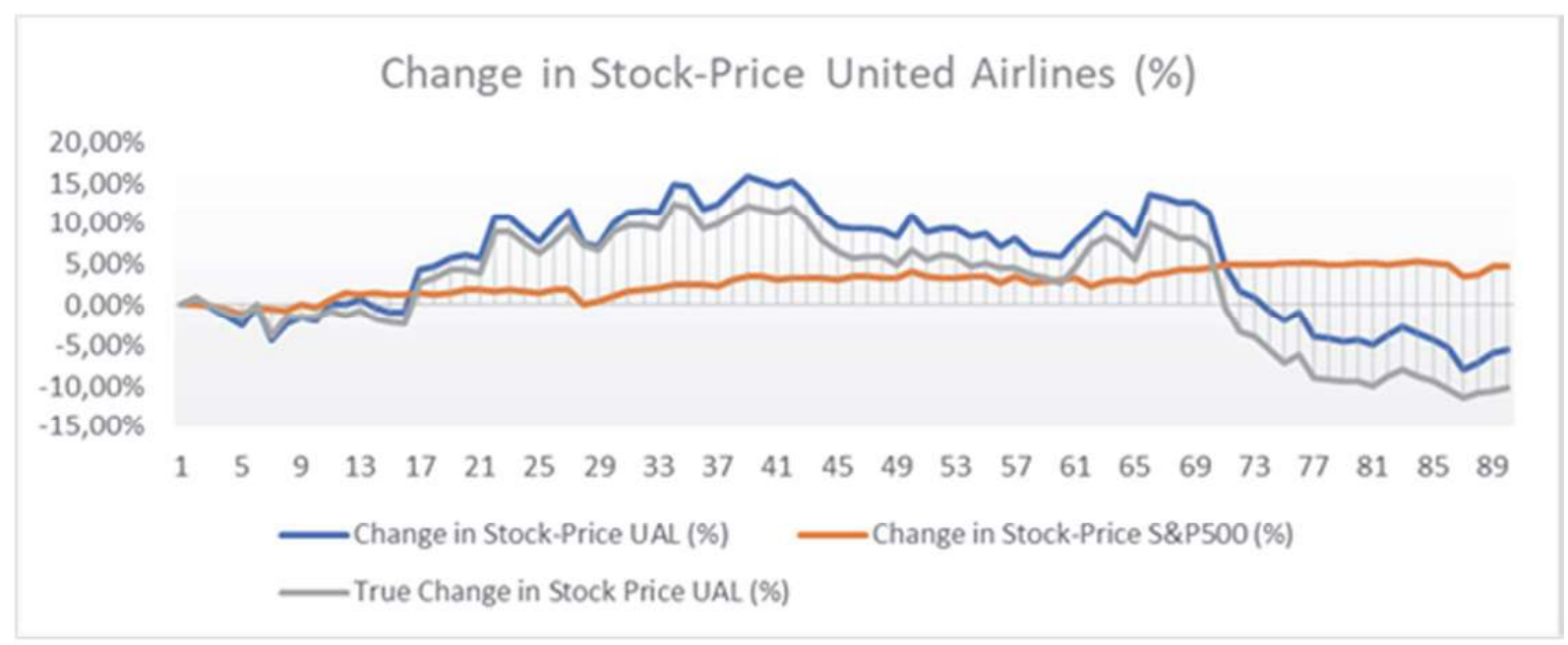

During the first few days of the crisis not much can be seen in terms of stock-price changes. After four days, we see a small negative swing of $-1.42 \%$, and after six business days, we see the largest negative swing of the initial crisis which is $-3.85 \%$. One can see that up until day 15 , there is a fairly consistent swing in price in between about $-0.5 \%$ to $-3.0 \%$. After this point something interesting happens, which is a fairly large upswing in stock-price. It can be observed that the price jumps to $4.24 \%$ on day 18 and to $9.06 \%$ on day 21 . This positive trend is going on for a fairly long time topping out at $12.18 \%$ at day 38 . Next interesting point happens between day 65 and day 80 . Here we see the stock-price dropping from $9.89 \%$ all the way down to $-10.03 \%$ respectively. As we can see in the graph, the price stays in that low region for the remaining part of the period.

So how did United Airlines handle this, very sudden, crisis that struck them? The first response happened the day after the crisis at the $9^{\text {th }}$ of April. The response was that the CEO of United Airlines, Oscar Munoz, sent out a letter to the United Airlines employees, explaining and describing the situation. In this letter he expressed his full support for the employees by saying: "While I deeply regret this situation arose, I also emphatically stand behind all of you" (Pignataro, 2017). In the letter he further argued that the staff acted according to protocol, and indirectly implied, that the passenger were to blame (Pignataro, 2017). This got the attention of the public, almost immediately, and sparked even more controversy in the eyes of the public (McCann, 2017). On Tuesday, the $11^{\text {th }}$ of April, United Airlines changed strategy towards the crisis, when Mr. Munoz provided another statement saying: "I want you to know that we take full responsibility and we will work to make it right" (McCann, 2017) following up with: "It's never too late to do the right thing" (McCann, 2017). This led to Mr. Munoz making a public announcement Wednesday the $12^{\text {th }}$ of April saying: "This can never - will never - happen again on a United Airlines flight. That's my premise and that's my promise," (McCann, 2017). Furthermore, United Airlines offered full refunds to all passenger onboard the plane, the same morning (Stack, 2017).

As a last note, an interesting point made by The New York Times in regards to the development of stock-price towards the end of the period of United Airlines following the crisis is that: "The results point to an underlying principle about the airline business: Passengers, by and large, look for the most convenient and cheapest fares, not which airlines claim to offer the best service" (Maidenberg, 2017) obviously referring to the lack of reactions from the stock-market in relations to the legitimacy issued, but huge reaction as soon as financial questions are posed. 


\section{ANALYSIS}

As explained in the methodology, what will be done in this section is to first discuss the different cases in relations to the model presented in the theory section, and then do a comparison of the different crisis situations. This section will be following the model quite closely, with the purpose of being easy to comprehend and compare. Note that the legitimacy questions will be discussed first, given that this will be used for the reaction discussion as well.

\section{Volkswagen}

As will be done with all the cases, the first thing to be discussed will be how the company handled the crisis. As described in the data review, Volkswagen had a rather slow reaction to the crisis which, according to Massey (2001), is the unideal way of handling a legitimacy crisis. It took two days for Volkswagen to make the initial move after the crisis broke which is, as mentioned, longer than what would be ideal (Massey, 2001). Despite this rather slow reaction time, it must be assumed that they had a CMP prepared considering that the first signs of the crisis were seen in May 2014, meaning more than a year before the crisis actually broke. As both Suchman (1995) and Massey (2001) argues, it would be desirable to react much faster than this, but on the good side of things, Volkswagen did seem to have a clear strategy in place when explaining the crisis.

As was described in the data review, they did not try to excuse themselves or in other ways try to move responsibility away from themselves but instead simply explain how sorry they were (Wattles, 2015), and that they were fully aware of the broken trust to their stakeholders and customers. They also argued that this kind of behavior would in no way be tolerated in the Volkswagen company, indicating that they definitely did want to take actions in this case, and not just hope it would pass - this means they are asking for forgiveness according to Massey's framework (2001). They would most likely know that, at this time, their legitimacy would be challenged on all levels, so simply believing a crisis of this magnitude would pass by itself would definitely be the wrong move, and could have been even costlier to the company. It was further described how the CEO, Martin Winterkorn, claimed to have had no knowledge of the manipulation going on inside the organization which would most likely be the approach most CEOs would take to a crisis like this, however, this will also put the company in quite a delicate spot, because this would mean either one of two scenarios. Either the CEO did, in fact, not know about this large-scale manipulation, which would mean that the company's leadership is highly incompetent, or the CEO did know about this, which would make the whole company untrustworthy. Despite picking the best of the worst options, the CEO was 'let go', which was probably the only option for the board of Volkswagen Group, with the hope of restoring some fate in the company. This could be seen as necessary, given that investors and stakeholders did demand some kind of response, and in cases like these, one would expect that someone should take the blame. In terms of speed, Martin Winterkorn was 'dismissed' only 5 days after the crisis broke, which seems a reasonably fast reaction.

All this obviously created a lot of question marks around the Volkswagen company. Both Corrado \& Jordan (1997) and Brown, et al., (1988) would argue that this would create enormous levels of uncertainty risk, thereby should cause a shock reaction in the market. Something like this have never before been seen in the Volkswagen Group, given that what is typically associated with them is great craftmanship (German Engineering) and honesty. For the investors, they would immediately know that this would have a large financial impact on the company, given that they would be required to recall a very large number of vehicles, but they would be very uncertain of further consequences. For example, they would know that there would most likely be further law suits following this, which could possibly cause even more financial damage to the company. Despite this, it would be uncertain how much this would impact sales figures down the line, and if Volkswagen would be able to regain lost trust from the customers. Despite what Massey (2001) would describe as a good effort from the Volkswagen Group, it would at this point be difficult to tell when the downward reaction to the crisis would stop.

When discussing crisis situations, for the sake of understanding the crisis, it can be beneficial to classify it. In this case it can be seen both as a legitimacy crisis and a financial crisis for the company. 
Even though it is not a direct threat to the company's survival, these are both highly important. It can be seen as a legitimacy crisis because it is challenging the company's general legitimacy, but also a financial crisis, because this directly caused a large financial deficit for the company.

To an extent, it can be important to look at the company's values following the crisis, because this can also be an indicator whether they are still struggling with the crisis. When discussing the crisis in relations to their visions, it is fairly evident that they do not want to be associated with this crisis and thereby associated with mistrust from the customers and stakeholders. This can actually be seen in most of their points made about strategy and values, for example the first, 'Existing Customers'. Here they say, that they want to keep the customers loyal towards the company, because they understand that this is the way to keep their position in the markets around the world, and can be interpreted in a way that shows that they have learned from their mistakes in the past. As was mentioned in the data review, it is interesting to see how much importance they put on the 'role for environment'. This should probably also be seen as them being responsible and did learn from their mistakes, and that problems like this will not happen in the future. This is probably a direct response to the emission scandal, and a way for them to try to regain customer and stakeholder trust.

So, did this crisis come as a surprise for the company and the market? This can be answered in two ways. As have been discussed, the company, and the market knew that there might be issues with some of the diesel cars sold in the United States, more than a year in advance of the crisis. It was also public knowledge, that there had been filed a lawsuit against Volkswagen concerning this emission problem some of the cars had, meaning the build-up to the crisis had been fairly long. This would mean, that the market could have foreseen a potential crisis coming down the line, thereby meaning it was not very surprising. However, the more relevant approach would be, that it was an enormous surprise for the entire market, because most investors would not have believed to which degree this crisis went. Furthermore, as have been previously discussed, Volkswagen is traditionally seen as a trustworthy company, that does everything by the book, which would further build on the surprise factor.

When one turns the focus towards the reaction from the market, what happened can only be described as a shock reaction from the market. According to Choi \& Hui (2014), this would be expected from a crisis that is this surprising. They further describe how something like this would be prone to see overreactions from the market. As was seen, the stock dropped dramatically by going down $-27.12 \%$ in only four days. That is a huge drop considering the size and strength of Volkswagen Group's stock. It is also evident, that despite the best efforts from Volkswagen, for example 'dismissing' the CEO and claiming responsibility for the crisis, it did not stop the stock-price from plummeting. From this point, the stock-price stayed down in the $-30 \%$ to $-37 \%$ range until about 60 days into the crisis. As was seen, after that it stabilized around $-19 \%$ to $-21 \%$. This would indicate that during the first 60 days, an overreaction from the market was observed, and that it did take a long time for the market to stabilize. This would also make sense because of the magnitude of the crisis. One thing that is worth noting, is that Choi \& Hui (2014) argues that the overreaction would only be seen shortly after the crisis struck, where in this case it took significantly longer for reaction to settle at a stabilized price.

It should be noted that because Volkswagen Group is such an important stock on the German market, it could have actually been part of the reason the DAX dropped simultaneously with the Volkswagen stock, thereby meaning that the true drop could be a bit larger than described in the data review, considering that the DAX is being subtracted from the Volkswagen stock-price. 


\section{TABLE 2 \\ SUMMARY OF VOLKSWAGEN}

\begin{tabular}{|c|c|}
\hline $\begin{array}{l}\text { Level of Uncertainty } \\
\text { information/risk }\end{array}$ & $\begin{array}{l}\text { High: } \\
\text { The only reason it is not classified as very high is that investors know } \\
\text { how many cars will have to be recalled, but they do not know exactly } \\
\text { how expensive this will be. Further, they do not know if there will be } \\
\text { lawsuits, and in that case how expensive that will be for the company. } \\
\text { There might also be speculations concerning to which extend this } \\
\text { dishonesty goes. }\end{array}$ \\
\hline Type of Crisis & $\begin{array}{l}\text { Legitimacy and Financial Crisis: } \\
\text { A legitimacy crisis in the way that it created huge trust issues for the } \\
\text { company. Financial because of the direct financial impact the crisis } \\
\text { caused the company because they had to recall a large number of cars and } \\
\text { faced lawsuits. }\end{array}$ \\
\hline Level of Surprise & $\begin{array}{l}\text { High: } \\
\text { It did come as a shock to the market how severe this issue was, despite } \\
\text { having known about the possible problems for a while. }\end{array}$ \\
\hline $\begin{array}{l}\text { How (fast) did the } \\
\text { market react? }\end{array}$ & $\begin{array}{l}\text { Shock Reaction: } \\
\text { It came as a huge shock to the market, reflected in the stock-price } \\
\text { plummeting down by }-27.12 \% \text { in only four days. }\end{array}$ \\
\hline CMP Prepared? & $\begin{array}{l}\text { Yes: } \\
\text { It seems as if Volkswagen had a clear strategy about how to approach the } \\
\text { crisis, despite a rather late initial reaction. }\end{array}$ \\
\hline Multiple events? & $\begin{array}{l}\text { No: } \\
\text { The information revealed the } 18^{\text {th }} \text { of September was the only major event } \\
\text { that happened. }\end{array}$ \\
\hline $\begin{array}{l}\text { Over- or } \\
\text { Underreaction? }\end{array}$ & $\begin{array}{l}\text { Overreaction: } \\
\text { During the first } 60 \text { days of the crisis, the stock-price fluctuated between - } \\
30 \% \text { to }-37 \% \text {, but after that point it stabilized between }-19 \% \text { to }-21 \% \text {. }\end{array}$ \\
\hline
\end{tabular}

\section{Wells Fargo}

As have been explained previously, the first thing that will be discussed is the reactions of the company, and that will remain the same for Wells Fargo. So how did they handle the crisis? They did follow one of the golden rules when handling a crisis, especially a legitimacy crisis, which is to act quickly and decisively. Massey (2001) describes how this is highly important in a legitimacy crisis, because it can lower the uncertainty that otherwise can surround a legitimacy crisis. As have been described, the first thing that happened was, that they immediately took responsibility for the crisis and what had happened in relations to the crisis. This would, according to Massey (2001), be the company asking for forgiveness. They did not try to fool the customers or stakeholders, by trying to transfer responsibility to somebody else, which can be considered a responsible way of handling the crisis. By doing this, they agree that the trust, and thereby the legitimacy from the customers and stakeholders, have been broken or the very least, been put into question, when they said, they would now focus on 'rebuilding customers trust'. From the theoretical perspective, this is the strategy that takes the complete responsibility and by that, hope that the honesty the company is now showing, will help them to regain what has been lost in terms of trust and legitimacy (Massey, 2001). As have been discussed to an extend by Suchman (1995), is that it is evident that the process of rebuilding trust can be a much harder challenge than gaining it in the first place. Therefore, having this decisive strategy can greatly help the company getting off to a good start in a bad situation. These actions can also be a great indicator about their CMP, because this is definitely a strong indicator that they did in fact have a prepared CMP. Furthermore, they 
did have plenty of time to prepare a suitable response strategy to the crisis, given that they did know the lawsuit was going on, and that they most likely would have known for a fair amount of time, that they would have to settle at some point. In terms of strategy, they did also stick to just one strategy, which can be seen as a well-prepared company.

When a company is in a situation like this, and they have taken the full responsibility, the customers and stakeholders would expect some actions being taken from the company, with the goal of making things right (Massey, 2001). In Wells Fargo's case, this also happened rather decisively. They back up the public statements by describing how they would solve the problem by stopping the 'sales incentive program', which can definitely be considered the general problem of the company. They also did mass firings as have been described, but the fact that they have had to fire more than 5300 employees can be seen in two ways. Either they are taking responsibility of wrongdoings in the company by letting people go, or there is an internal problem with the company culture, because it is not common that a company have to fire that many people because of 'shady' behavior. Either way, it is difficult for the company to deny that the crisis can be considered a direct problem with the internal structure in the company. This would also question the management of the company, because people would expect them to know about these internal issues, thereby putting the CEO in the line of fire. This meant that Wells Fargo did the only logical step and dismissed the company's CEO a short while after the crisis broke.

In this case it is also interesting to point out what Wells Fargo themselves present as what they stand for - the 'Relationships that last a lifetime', 'Expertise and guidance to help our customers make confident decisions' and 'Going the extra mile to do what's right'. This should be interpreted as an extension to their overall vision for the company, 'We want to satisfy our customers' financial needs and help them succeed financially'. They describe this as have been the same for more than 20 years, which means it was not created as a consequence of the crisis. Both Suchman (1995) and Massey (2001) would argue that this would make the crisis even worse in terms of questions to their legitimacy, given that what happened is doing completely the contrary to what they stand for as a company - thereby also demanding more serious actions taken from the company to recover. It is typical that when a CEO is dismissed in one way or the other, it typically creates a great deal of uncertainty risk for the shareholders, but one could argue that in this particular case, it would actually minimize the risk, given that this would show a certain 'drive' from the company, and showing that 'we do not tolerate this kind of actions in the company'.

When discussing the level of surprise that this case had, it cannot be said that this came as a big shock to the market. This is reflected in two ways. First, it is evident that the stock-market did not seem to react as fiercely as one could have feared, from the Wells Fargo perspective. The drop was a steady downflow, and after a certain negative point the price started to steadily rise until it seems to stabilize in a positive region compared to before the crisis. This can be described, only as a controlled process. To this extend, Choi \& Hui (2014) would argue that this would be the expected result because a non-surprising or even a moderately-surprising event would most likely not cause a shock reaction, and is less likely to cause an overreaction in the market. Second, given that the accusations of the Wells Fargo company, having major internal issues have been going on for a long time, combined with the ongoing lawsuit against them, it can come as no big surprise that this could happen. One thing that could make this a surprise for the market is that all the way up until this point in time, it has only been accusations, and no one in Wells Fargo's management department have been agreeing that there might be issues, however agreeing to settle the lawsuit means that they accept the accusations, thereby creating the surprise and uncertainty.

When moving on to discuss the stock-price development, it can be seen that these direct and decisive actions have seemed to pay off. As was described, after 18 days we identified the lowest point of the crisis when it went down to $-10.79 \%$. The way that the market reacted to the crisis was quite interesting, given that no major, one-day price drop was observed. This would suggest that the market indeed expected this crisis, and were not shocked with the fact that Wells Fargo were guilty of the charges. Another explanation that there was no shock reaction from the market could be because Wells Fargo acted so quickly. This would be a helpful factor for worried investors, because it can minimize the newly risen uncertainty risk in the company. According to Corrado \& Jordan (1997) lowering the unknown information would also lower the risk, hence it would seem logical that the stock-price would not 
experience a shock reaction. Furthermore, it could be a decisive factor that one kept seeing actions from Wells Fargo, and in that way telling the customers and stakeholders that they were in charge, meaning minimizing the uncertainty risk further (Corrado \& Jordan, 1997). Despite that Choi \& Hui (2014) would suggest that a non-surprising event, as well as an event not causing a shock reaction, would not be as likely to cause an overreaction, what was observed was something that could in fact be classified as an overreaction in this case. The price fell too much considering that the stock-price went back up at stayed positive after a fairly short time. This could be the result from risk averse investors that would panic-sell the stock as would be argued by Brown et al. (1988). A possible explanation for the sudden positive rise after the initial drop, could be that investors were relieved that the crisis did not cause any further damage, or it could be the mass firing releasing more money in the company, which is fairly common in a mass layoff situation.

\section{TABLE 3 \\ SUMMARY OF WELLS FARGO}

\begin{tabular}{|l|l|}
\hline $\begin{array}{l}\text { Level of Uncertainty } \\
\text { information/risk }\end{array}$ & $\begin{array}{l}\text { Moderate to high: } \\
\text { Because they acted highly irresponsible and against their own moral code, } \\
\text { their legitimacy and trustworthiness have been severely damaged. } \\
\text { Investors would question their practices, and even their capabilities of } \\
\text { running the company in the future. }\end{array}$ \\
\hline Type of Crisis & $\begin{array}{l}\text { Legitimacy: } \\
\text { Despite this crisis having obvious financial question marks posed, it is } \\
\text { primarily trust issues that define this crisis. }\end{array}$ \\
\hline Level of Surprise & $\begin{array}{l}\text { Moderate: } \\
\text { The fact that they did settle the lawsuit might have created some } \\
\text { surprises, but as reflected in the stock-price, it is not come as a big shock. } \\
\text { The reason for that is that these accusations have been going on for a long } \\
\text { time. }\end{array}$ \\
\hline $\begin{array}{l}\text { How (fast) did the } \\
\text { market react? }\end{array}$ & $\begin{array}{l}\text { Slow and steady: } \\
\text { The reaction from the market were rather slow and linear. As we did not } \\
\text { see any shock, the stock-price went down to - } 10,79 \% \text { after } 18 \text { days, and } \\
\text { then steadily climbed back up. }\end{array}$ \\
\hline CMP Prepared? & $\begin{array}{l}\text { Yes: } \\
\text { It seemed quite clear that Wells Fargo had a well-prepared CMP for this } \\
\text { crisis situation. This can be seen in their decisive actions right after the } \\
\text { crisis struck, and them not switching strategy at any time during the } \\
\text { crisis. }\end{array}$ \\
\hline Multiple events? & $\begin{array}{l}\text { No: } \\
\text { The only relevant event was the initial event, in terms of this crisis. }\end{array}$ \\
\hline $\begin{array}{l}\text { Over- or } \\
\text { Underreaction? }\end{array}$ & $\begin{array}{l}\text { Fairly clear overreaction: } \\
\text { The market seemed to have overreacted to the crisis despite the slow } \\
\text { development of the crisis. After the steady drop to -10.79\%, the stock } \\
\text { climbed back up and stabilized in the positive region compared to before } \\
\text { the crisis struck. }\end{array}$ \\
\hline
\end{tabular}

\section{United Airlines}

As have now been established, the first thing will be discussing how the company handled the crisis. Their initial response was in a way not very effective, in terms of toning down the media storm surrounding the company at the given time. As have been presented, they argued or rather implied that the cause of this whole situation was a misbehaving individual on their plane, and that how they handled the 
crisis was actually completely justified, and completely according to their protocol. However, as is now known, this was very ill received by the public and the media, and caused the company even more harm and bad publicity than the initial crisis. Therefore, the company and CEO almost immediately had to change their response strategy. He simply chose to take all the responsibility and simply hope that the honesty would help in getting the public to forgive him and the company. They further discussed how they would revisit their internal protocols and procedures, which is also a way of telling the public that they know that something needs to change to 'make things right' as the CEO says. This strategy seemed more effective in many ways, because what made the problem go from bad to worse was the fact that they started to 'accuse' the passenger of wrong doings instead of immediately taking responsibility, and this would help to at least settle that issue. According to Massey (2001), this would be the complete opposite of what one would want in that situation. He would argue that the company should stick to the decided strategy, and not change in the middle of the crisis, because this would just create more doubt about the company's legitimacy - which seemed to be the case for United Airlines. If looking at this from a theoretical perspective, it would seem that the company were about to jeopardize their legitimacy on all three levels (pragmatic, moral and cognitive) (Suchman, 1995). Furthermore, it is important to understand the norms in the region for this case. In America, the social norm is, as it is in most of the world, the customer is in general right, and especially when you have paid for a service - one would expect to receive that service. In this case, the customer will expect or even demand, that if they have already paid for their ticket, they should not be forced to give up that ticket if they do not want to. Therefore, in this case, the public will most likely take the side of the customer and thereby harm the company, even if the customer also acted inappropriate. The actions that United Airlines eventually took to stop the crisis from escalating any further, obviously did not make the problems go away just like that, but it did seem to help a bit in the recovery process. Arguably, a further reason that this particular crisis was so ill-received in the eyes of the public could also be that the issue of overbooking commercial airlines is an issue and an annoyance that the American people are all dealing with, with most of the American airlines, and this just seems to lower the standards of the aviation service even further. It can be argued that in these legitimacy cases, it is often more impactful if the customers can sympathize with the 'victim', and set themselves in their place - and because of all these overbooking issues, that is definitely not difficult for the American people.

As it turned out, it did not seem as United Airlines had a clear CMP or at least were not able to identify the crisis correctly when it initially struck. It can be argued that they got off to a very bad start in the crisis, where they identified the upcoming crisis as just a small issue that would not harm the company, and just go away by itself. This was underestimating the situation and the power of social media completely. If the company had had a better crisis response procedure, and a clear-cut understanding of the crisis, they might have avoided some of the bad publicity. As have been discussed by Massey (2001), the CMP is in place as a tool to minimize damage to the company, and utilizing it correctly can help with that. In this case it is fairly evident that their initial response did not yield the desired result compared to if they actually had such a CMP in place. On the other hand, what is surprising considering Massey's (2001) theory, is that this did not have further impact on the company.

When it comes to discussing a surprise factor for a case like this, it is obviously not something that has been long underway in the traditional sense, because the incidence happened, and the world knew within hours, as just mentioned. But looking at it from a broader perspective, it can be argued that an incidence like this was not as surprising as people would imagine. It is not a secret that airlines are seeking to maximize profit, often compromising the comfort of the customers or the staff, and the American airlines are definitely not innocent of this either. As have been discussed in length, the overbooking of commercial airlines is very common practice in the United States, to maximize the profit, which have often yielded great discomfort of the passengers. Therefore, it is not a surprise that the airlines would at some point face these types of incidences in their desire to maximize said profit. That said, it is however a bit of a surprise that they would go to that distance to ensure this. To this extend, it is not the first time that United Airlines face legitimacy issues, thereby further lowering the surprise factor of the 
incidence. According to Choi \& Hui (2014), this would mean that it would most likely not create an overreaction in the market, which also seemed to be the case.

For an investor or a stakeholder's perspective, a crisis like this definitely created some uncertainty information and some uncertainty risk. They would now have to consider if this crisis would have any implications on their investment down the line, considering that the crisis was purely 'bad publicity' and not any direct economic problems. Their main concern in this case would be if large portion of potential customers would choose to not go with United Airlines in the future because of this situation, and thereby risking that sales would go down for United Airlines. They could also start wondering if this incidence would cause potential business partners to not pick United Airlines as a partner in the future. The reason that this could be an issue that is worth considering is that, as explained in the theory (Massey, 2001), legitimacy problems of a business partner can also have a negative influence for the own company's business and legitimacy. If this happened, it would obviously also create financial problems for, in this case, United Airlines. All these concerns are reflected in the stock-price after a crisis have struck and will give an indicator of what the market thinks, and as have been observed in the price drop of $-3.85 \%$, this was not a very big drop. This could be an indicator of several things, for example that investors are not too concerned with purely legitimacy problems for larger companies like United Airlines. As was shown in the data review, there were arguments saying that this was an example of people being more concerned with having cheap flights than ethical behavior of the company. This would also be the prediction from both Brown, et al., (1988) and Corrado \& Jordan (1997). As this is not creating much uncertainty risk, the chance of an overreaction from the market is smaller.

What we saw, in the case of United Airlines, was actually really interesting when discussing the stock-reaction in the market. As just mentioned, there was no large negative change in stock-price immediately, the largest drop being the $-3.85 \%$ after 6 business days. Considering how poorly the initial response to the crisis was, from a legitimacy standpoint, this seems surprising. What is even more interesting is that the stock-price actually went up during the first few days - and again after the $-3.85 \%$ drop. The explanation for this can be argued to be the nature of the crisis itself. The nature of this crisis was that it was created by the online social medias, which meant that in a matter of hours most people connected to the internet saw the disturbing pictures of a man being dragged from a plane with blood running down his face. This would also be explained by what Choi \& Hui (2014) found, that underreactions could often be observed when an event is less surprising. Despite this, it might have taken longer for people and investors to pick up the serious side of the situation. One would expect that this would create more uncertainty risk, but apparently it did not, and instead the stock-price actually rose quite dramatically after the $-3.85 \%$ drop. This could be explained by investors being relieved that not more happened in relations to the crisis, and arguably, if a media crisis like this does not damage the company more, it would indicate strength in the company. If that is the case, the legitimacy crisis actually ended up having a positive outcome for the company, instead of a negative, despite the CMP issues that Massey's (2001) theory presented. Toward the end of the 90-day cycle, there is a rather severe drop in the stock-price again, however this does not seem to have anything to do with the legitimacy problems that were created during the crisis or any follow-up to that crisis.

So, to put all this into perspective, how did the market react to this crisis? Well, in some ways the one-day $-3.85 \%$ drop could be classified as an overreaction to the crisis, because as it would turn out, the financial consequences from a pure legitimacy crisis were very minimal, and apparently more would be needed to shake up a company of this size. This could be the reason that the price did not drop further in the first place, and that it was only one day that the price went that low. One could further speculate in, if the stock-market overvalued the information that United Airlines did not get punished harder by a legitimacy crisis at this scale, and thereby inflated the price a bit before it sunk back down, but this is mere speculation. However, this does seem to go in line with the theory of De Bondt \& Thaler (1985), that the too big price increase is followed up by a larger price decrease later. 
TABLE 4

\section{SUMMARY OF UNITED AIRLINES}

\begin{tabular}{|l|l|}
\hline $\begin{array}{l}\text { Level of Uncertainty } \\
\text { information/risk }\end{array}$ & $\begin{array}{l}\text { Moderate to Low: } \\
\text { Only a small level of uncertainty information/risk were created in } \\
\text { relations to this crisis. This only generated questions towards how much it } \\
\text { would impact potential customers, and would that compromise earnings, } \\
\text { however this was not too big of a concern. }\end{array}$ \\
\hline Type of Crisis & $\begin{array}{l}\text { Legitimacy: } \\
\text { This was a legitimacy crisis only, given that it did not have any direct } \\
\text { impact on the financial aspects of United Airlines. The financial aspect } \\
\text { would only be impacted by the potential lawsuit of the passenger and the } \\
\text { potential loss in sales due to the bad publicity. }\end{array}$ \\
\hline Level of Surprise & $\begin{array}{l}\text { Moderate: } \\
\text { Being familiar with the service and procedures of airlines in the United } \\
\text { States it is not very surprising that events like this could occur. This was } \\
\text { also reflected in the stock-price following the event. }\end{array}$ \\
\hline $\begin{array}{l}\text { How (fast) did the } \\
\text { market react? }\end{array}$ & $\begin{array}{l}\text { Small and slow reaction: } \\
\text { There was no immediately reaction from the market, and only a small } \\
\text { one-day drop of -3.85\% were observed after the event. }\end{array}$ \\
\hline CMP Prepared? & $\begin{array}{l}\text { No: } \\
\text { It did not seem as if United Airlines had a plan prepared, given that they } \\
\text { did not react effectively to the crisis in the beginning, forcing them to } \\
\text { change strategy a number of times. If they had a plan, they did not } \\
\text { manage to identify the potential crisis right, causing them to choose a } \\
\text { non-optimal strategy from the beginning. }\end{array}$ \\
\hline Multiple events? & $\begin{array}{l}\text { No: } \\
\text { The only relevant event was the initial event, in terms of this crisis. }\end{array}$ \\
\hline Over- or & $\begin{array}{l}\text { Small to non-overreaction: } \\
\text { It was argued that the small -3.85\% drop after 6 business days, was a } \\
\text { small overreaction given that there were no financial consequences for the } \\
\text { company, reflected in the following days, that showed a long price } \\
\text { increase. }\end{array}$ \\
\hline
\end{tabular}

\section{Comparison}

There are many interesting outcomes to discuss in regard to these different crisis situations, therefore discuss their differences and similarities, then discuss why these may occur. These will be based on what can be found in the summary of each case. To make it easy to follow, table 5 is a combined summary of the three case-models discussed in the analysis, this being without the explanation: 
TABLE 5

COMBINED COMPARISON

\begin{tabular}{|l|l|l|l|}
\hline Summary: & Volkswagen: & Wells Fargo: & United Airlines: \\
\hline $\begin{array}{l}\text { Level of Uncertainty } \\
\text { information/risk }\end{array}$ & High & Moderate to high & Moderate to Low \\
\hline Type of Crisis & $\begin{array}{l}\text { Legitimacy and } \\
\text { Financial Crisis }\end{array}$ & Legitimacy & Legitimacy \\
\hline Level of Surprise & High & Moderate & Moderate \\
\hline $\begin{array}{l}\text { How (fast) did the } \\
\text { market react? }\end{array}$ & Shock Reaction & Slow and steady & $\begin{array}{l}\text { Small and slow } \\
\text { reaction }\end{array}$ \\
\hline CMP Prepared? & Yes & Yes & No \\
\hline Multiple events? & No & No & No \\
\hline $\begin{array}{l}\text { Over- or } \\
\text { Underreaction? }\end{array}$ & Overreaction & Overreaction & $\begin{array}{l}\text { Small to non- } \\
\text { overreaction }\end{array}$ \\
\hline
\end{tabular}

Given that it is primarily the over- or underreaction in the market this paper is interested in, that will be the first thing discussed, and be of focus throughout this comparison. As can be clearly observed in the table above, an overreaction was observed both in the Volkswagen case as well as the Wells Fargo case. In the United Airlines case, only a fairly small overreaction was observed, and one could argue that this was not even an overreaction given that it was only a one-day drop, in an otherwise fairly stable time for the stock. So why could all this be? First, it is interesting to discuss the cases compared to the CMP framework prepared by Massey (2001), meaning whether or not the company had a proper CMP prepared. What was found for these cases was, that only United Airlines did not have a proper CMP prepared, but despite that, they were the only company that managed to have almost no negative outcome from the crisis, and even a positive outcome was observed for a fair amount of time. This is definitely interesting, considering how bad United Airlines handled the crisis, and that actually had second to no impact on the stock reaction. As mentioned, Massey (2001), would argue that this would mean the company could risk losing more legitimacy, as well as increasing the uncertainty risk. If this is the case, both Corrado \& Jordan (1997) and Brown, et al., (1988) would argue that a strong reaction from the market could be likely, but this did not happen. It is important to note that these crisis situations are different in their nature, but definitely interesting to see that the only company without a proper CMP came out of the crisis in the best condition, as this is contradictory to what the theory of Massey (2001), Brown et al., (1988) and Corrado \& Jordan (1997) would suggest. This could somewhat indicate that the importance of a proper response strategy is minimal, and something else must be much more influential to how the market reacts to a crisis event.

So, could the kind of crisis impact how the market reacts to the event? The examples in this paper is similar in some cases when it comes to the 'type of crisis' but definitely not exactly the same. In the Volkswagen case, it was clearly a case of both a legitimacy crisis as well as a financial crisis, where Wells Fargo were primarily a legitimacy crisis, but had also small financial issues linked to it, where the United Airlines was purely a legitimacy crisis. Comparing the crisis to how the market reacted can be interpreted in multiple ways, a few of which will be discussed. In the market, the largest impact of the crisis was by far the Volkswagen crisis, and the reason that this was so much worse than the other two crises could be that the crisis compromised both financial as well as legitimate interests for the company and its stakeholders. The crisis of Volkswagen also came as a shock to the market, as was seen in the way the stock-price plummeted dramatically during the first few days. For the Wells Fargo case a steady drop was observed but in this case, it was mostly a legitimacy crisis, but it definitely also had financial aspects to it. In the United Airlines case, it was purely a legitimacy crisis, however, it did not seem to have any impact to the company's stock-price beside the small, one-day drop that have already been discussed. According to Choi \& Hui (2014), each level of surprise seems to reflect the reaction from the market 
quite linear, meaning the more surprising the event, the stronger the reaction from the market. From an economic stand point it would make sense that when the financial aspects of the company could be compromised, it would be reflected in the stock-price, but in terms of legitimacy it seems to vary. For Wells Fargo, it was mainly a legitimacy issue, but it had a much larger impact on the stock-price than the United Airlines event. This could obviously be partly due to the much larger scale of which the Wells Fargo crisis was, but an impact on the United Airlines stock would still be expected according to the legitimacy theory of Massey (2001), and Corrado \& Jordan (1997). This seems as a rather surprising outcome.

When discussing legitimacy, there would also be other factors influencing the 'importance' of the legitimacy itself. For example, how the market reacts to loss of legitimacy could also vary from field of business to other fields. For example, in this case, there are also some clear differences between the companies, concerning how customers and stakeholders view the field of which the company operate, and by that, the company. This can be linked with the ideas of Piccoli, et al., (2017), because they argue that the reaction from the market is often connected with what people's previous beliefs are. For example, both for Wells Fargo, who operates in the field of banking, and United Airlines, who operates in the aviation field, can be seen by the market as unethical profit-driven fields, where Volkswagen have another reputation as a company. Volkswagen is often seen as honest and legitimate, also causing larger problems when they are displayed in a non-legitimate light. The ideas of Piccoli, et al., (2017) could be a reason that no large impacts were seen in the United Airlines case, and the bigger impacts in the Volkswagen case.

One of the big questions in all these cases, is the level of uncertainty risk or uncertainty this has created, because this would seem as having a big impact on how the market would react. Following how the market reacted, compared to the described level of uncertainty risk created, seems quite similar as have been previously described. In the Volkswagen case, a high level of uncertainty risk was created, and it was also the case with the largest drop in stock-value. For Wells Fargo, a moderate to high level was observed, and this also created a large drop in stock-value, though not as big as in the Volkswagen case. And lastly a moderate to low level was observed in the United Airlines case, which was reflected in the stock-price, by causing a very small impact to it. From this study, it seems as if the level of uncertainty risk, and uncertainty information is strongly correlated with how the market reacts to the crisis, hence backing the ideas presented by both Corrado \& Jordan, (1997) and Brown, et al., (1988). There will obviously be more to it than this, but worth noting.

As have been briefly mentioned, the surprise factor is also highly important to discuss. As both Choi \& Hui (2014) and Piccoli (2017) believe, this will often be a decisive factor when it comes to the questions of overreactions in the stock-market. What was observed in the cases, was that Volkswagen's case was highly surprising and the reaction from the stock-market showed that, as well with what can only be described as a shock-reaction. The other two cases were observed as both being moderate in terms of how surprising the events were. For Wells Fargo, the reason was that the case had been going on for a fair amount of time, and at the point of the settlement, many investors would most likely be prepared that this might be the case, also considering the reputation of Wells Fargo. In the United Airlines case, the shock for the investor seemed moderately low, even though the medias around the world showed these shocking images of the passenger being dragged from the plane. The reason for this could be, as was argued, that the standard of the airlines is so low in the United States in the first place, that most would not be very surprised that an event like this might occur. Going back to the Volkswagen case, this was also something that was going on for a while, but the reason that it shocked the market in the way it did, was that most investors and stakeholders did not seem as if they knew how bad the situation actually was. All of this, give an indication that the level of surprise will most likely affect the reaction on the market and by that also increase the risk of an overreaction from the market. It seems as the level of surprise correlates with the ideas of Choi \& Hui (2014) to some extent, because the shock reaction from the market towards Volkswagen would be exactly as they would predict. However, the moderately surprising reaction in the Wells Fargo case, did also spawn an overreaction, even though Choi \& Hui (2014) would predict this to be more likely to underreact. 
As it turned out, what was observed was that all the crisis situations can be argued to be legitimacy crisis situations, however, there are much more to it than that. Only looking at if a crisis is a legitimacy crisis, will not solely allow the researcher to identify how the market will react, but it could definitely seem as if it could affect the reaction, at least on some fields of operation.

On a final note, what is interesting, is that despite every difference between the companies, it seems as the stock-price would go back up after the initial drop. This was obviously most evident for the Wells Fargo and United Airlines case, but the same behavior was observed in the Volkswagen case, it just took longer for the market to stabilize.

\section{CONCLUSION}

As this paper was created as a qualitative exploratory case-study, the goal was to get general ideas of how the market responded to a legitimacy crisis, and evaluate the reaction from the stock-market during the following period of time. The main reason for doing this study, is that the author of this paper found a big gap in the previous research, when it comes to overreaction in the stock market combined with legitimacy crisis events. Given that many authors have drawn many different conclusions to how the market overreacts, it seemed odd that no one have looked at this specific topic. Thereby this paper will provide a steppingstone to explore this area of research even further. As this was with the purpose of looking for similarities, the cases had to be similar in some ways, therefore the pick of legitimacy crisis situations, given that this seemed a fairly unexplored area. What was found and observed was very interesting in many ways.

The first interesting point that was stumbled upon was that having a proper crisis response strategy, or a CMP have minimal effect on the change to the stock-price. In relations to the first research question, what was observed was that the United Airlines handled their crisis by far the worst, but at the same time was the only company that did not suffer any big negative reaction from the market. Wells Fargo handled the crisis the best out of the three companies that was studied and even though they would still suffer a negative reaction from the stock-market, it was more steady and slow reacting compared to Volkswagen, that reacted a bit late to the crisis in terms of crisis response strategy. This leads back to the initial statement that it did seem as if the preparation of a CMP would have a small impact on how the market reacted. Furthermore, what was observed seemed to hint that solely the legitimacy issues have a small impact when it comes to stock-reactions and that the larger reactions are only observed when it would have large financial complications as well. It seemed as there needed to be some direct financial consequence for it to have an impact on the stock-price. This said, there would be reason to believe that this could change depending on the field of which the company does business, for example the banking industry might be seen as more illegitimate than well-known German car manufactures.

It seemed as the most consistent result came when discussing the level of uncertainty information or uncertainty risk. In this term, it seems as the more uncertainty risk a crisis creates, the bigger the impact on the stock-price. This would also make sense from an economic and theoretical standpoint, because more risk means the chance of losing money on the investment and given that the stock-market is in general risk averse, this seems logical. What was observed in this paper was that all three cases experienced some sort of overreaction from the market, even though the United Airlines reaction was fairly small. This does, however, come with a great deal of risk. Usually what happens is that the crisis creates a great deal of uncertainty information and that leads to more uncertainty in the stocks future.

\section{Limitations and Suggestions for Further Studies}

There will obviously be limitations to a study like this, as there will be with any kind of study. The first that is worth mentioning is that when doing this exploratory case-study, it will not be possible to give any strong indications whether or not, what is shown in the study is the actual trend in the market. For that, further research is required. This should not be seen as an issue, given that the goal of this type of study is not to give any definite answer, but to explore. Furthermore, only having three different cases 
will obviously run the risk of showing something not close to the truth, despite backing findings up with acknowledged theory. As have been mentioned, the specific cases were picked as they seemed different in their nature, with the purpose of lowering this risk, as is suggested in the theory. To this extend, there can be a limitation in the measurement of the stock-movements in the market. As Piccoli et al. (2017) says, using a one size fits all approach to the comparison can be limiting. What this means, is that it is not necessarily the same impact on a company when they drop $10 \%$ in stock-price. For a smaller company, a $10 \%$ drop could be not that noticeable because the stock-price often fluctuate quite a bit, where for a larger company, it might be disaster.

There are also limitations to the data used for the analysis, given that not all the desired data is public information. For example, in this case-study it could have been helpful to know more specifically about each company's crisis management program and if they actually had a CMP prepared for the crisis event (Massey, 2001). This cannot be accessed, meaning one will have to rely on educated guesses, by using the data publicly available. This would mean looking at how they handled the crisis, but from an outsider's perspective. It could have been that United Airlines had a great CMP, but simply did not manage to identify the crisis correctly, as have already been discussed.

When discussing the theoretical framework, there are definitely also limitations, as discussed in the description of the model. As discussed, the goal of the framework is not to provide a highly strict model that will yield the exact same result no matter who is using it, but rather to provide a general model that will keep the analyst within the same boundaries when analyzing. This is because it remains a tool for use for an exploratory case-study, and thereby require that the analyst can have some flexibility. This will provide better options to come up with potential new hypothesis.

One final limitation that case-studies are often subject to is the risk of being more 'experimenter biased' than regular quantitative studies. The reason for this, is that there will be much more interaction between researcher and 'subject' (Blaxter, et al., 2006). For this paper, the issue has been considered by preparing the theoretical framework that every case should be compared to. This is a way to make a more objective measure for each case, thereby eliminate some of the possible bias (Blaxter, et al., 2006).

All these limitations aside, there were very interesting findings in this paper, which would call for further research. CMP does not make any difference to the outcome of a legitimacy crisis.

As was observed in the paper, the CMP did not seem matter much in terms of immediate stock-price drops so why is there so much theory discussing the importance of this? It would be interesting to explore this further, to examine how much this matters.

- Companies in illegitimate fields such as banking and aviation, experience a smaller stockprice drop than a similar crisis would create in a legitimate field, when it comes to legitimacy issues.

- There are no financial consequences when acting illegitimate, if the company is already considered illegitimate.

This can be seen as an extension to the previously asked question. A minimal reaction was observed from United Airlines, and during this study it was discussed, if the field of which the company operated had any influence on that. It seems possible, given that there were no changes or at least very minimal negative effects for United Airlines, but strong reactions in the Volkswagen case. Bear in mind there were more differences between the two cases that just the reaction.

- The level of uncertainty risk correlated strongly with the reaction from the stock-market.

This was one of the areas where this case-study provided fairly clear suggestions to how the trend in the market is. Therefore, this is a fairly obvious suggestion, given that the trends were so clear. One thing that needs to be more precisely described in a further study, is a more explicit way of measuring level of uncertainty risk/information, if the idea is to use a quantitative approach for this.

- It will take longer for a stock-price to stabilize if a crisis can both be defined as a legitimacyand a financial crisis.

What was observed primarily between Wells Fargo and Volkswagen, was that, despite both reclaiming some-, or the whole lost stock-price territory, the Volkswagen case bounced back much 
slower. A possible explanation for this would be that it was a strong legitimacy as well as a financial crisis for the company, compared to the Wells Fargo case, where it was mostly a legitimacy crisis.

\section{REFERENCES}

Akerlof, R. (2017). The importance of legitimacy. The World Bank Economic Review, 30, S157-S165.

Ashforth, B. E., \& Gibbs, B. W. (1990). The double-edge of organizational legitimation. Organization Science, 1(2), 177-94.

Blaxter, L., Hughes, C., \& Tight, M. (2006). How to research (3rd ed.) In Blaxter L. (Ed.), Milton Keynes: Open University Press.

Bloomberg. (2017). Company overview of United Airlines, inc.. Retrieved 10/20, 2017, from https://www.bloomberg.com/research/stocks/private/snapshot.asp?privcapId=26977

Brown, K. C., Harlow, W. V., \& Tinic, S. M. (1988). Risk aversion, uncertain information, and market efficiency. Journal of Financial Economics, 22(2), 355-385.

Cavallos, D. (2017). United Airlines must have paid big bucks for dr. dao's silence. Retrieved 10/20, 2017, from http://edition.cnn.com/2017/04/28/opinions/united-airlines-settlementcevallos/index.html

Choi, D., \& Hui, S. K. (2014). The role of surprise understanding overreaction and underreaction to unanticipated events using in-play soccer betting market. Journal of Economic Behavior \& Organization: JEBO, 107(2), 614-629.

Conrad, J., \& Kaul, G. (1993). Long-term market overreaction or biases in computed returns? The Journal of Finance: The Journal of the American Finance Association, 48(1), 39-63.

Coombs, W. T. (1999). Ongoing crisis communication: Planning, managing, and responding. Thousand Oaks, CA: Saga.

Corrado, C., \& Jordan, B. (1997). Risk aversion, uncertain information, and market efficiency. Review of Quantitative Finance and Accounting, 8(1), 51-68.

Cowley, S. (2016). Wells Fargo's reaction to scandal fails to satisfy angry lawmakers. Retrieved 10/18, 2017, from https://www.nytimes.com/2016/09/30/business/dealbook/wells-fargo-ceo-johnstumpf-house-hearing.html

Creswell, J., \& Maheshwari, S. (2017). United grapples with PR crisis over videos of man being dragged off plane. Retrieved 10/20, 2017, from https://www.nytimes.com/2017/04/11/business/unitedairline-passenger-overbooked-flights.html

De Bondt, W. F. M., \& Thaler, R. (1985). Does the stock market overreact? Journal of Finance, 40(3), 793-805.

Deephouse, D. L., \& Suchman, M. (2008). In Greenwood R., Oliver C., Suddaby R. and Sahlin K. (Eds.), Legitimacy in organizational institutionalism

Dwyer, K. (2017). Timeline: How the Wells Fargo scandals unfolded. Retrieved 10/18, 2017, from http://www.mcall.com/business/mc-biz-wells-fargo-timeline-20170802-story.html

Egan, M. (2016). 5,300 Wells Fargo employees fired over 2 million phony accounts. Retrieved 10/18, 2017, from http://money.cnn.com/2016/09/08/investing/wells-fargo-created-phony-accountsbank-fees/index.html

Egan, M. (2017). Wells Fargo uncovers up to 1.4 million more fake accounts. Retrieved 10/18, 2017, from http://money.cnn.com/2017/08/31/investing/wells-fargo-fake-accounts/index.html

Egan, M., Wattles, J. \& Alesci, C. (2016).

Wells Fargo CEO John Stumpf is out. Retrieved 10/18, 2017, from

http://money.cnn.com/2016/10/12/investing/wells-fargo-ceo-john-stumpf-retires/index.html

Ewing, J. (2015). Volkswagen C.E.O. Martin Winterkorn resigns amid emissions scandal. Retrieved 10/16, 2017, from https://www.nytimes.com/2015/09/24/business/international/volkswagenchief-martin-winterkorn-resigns-amid-emissions-scandal.html

Fama, E. F. (1965). The behavior of stock- market prices. The Journal of Business: The University of Chicago Press, 38(1), 34-105. 
Forbes. (2017). United continental holdings on Forbes lists. Retrieved 10/20, 2017, from https://www.forbes.com/forbes/welcome/?toURL=https://www.forbes.com/companies/unitedcontinental-holdings/\&refURL $=$ \&referrer=

Forbes. (2017). Volkswagen group on Forbes lists. Retrieved 10/16, 2017, from https://www.forbes.com/companies/volkswagen-group/

Forbes. (2017). Wells fargo on Forbes lists. Retrieved 10/18, 2017, from https://www.forbes.com/companies/wells-fargo/

Kollewe, J. (2015). Volkswagen emissions scandal - timeline. Retrieved 10/16, 2017, from https://www.theguardian.com/business/2015/dec/10/volkswagen-emissions-scandal-timelineeventshttps://www.theguardian.com/business/2015/dec/10/volkswagen-emissions-scandaltimeline-events

Lartey, J. (2017). United Airlines passenger violently dragged from seat on overbooked flight. Retrieved 10/20, 2017, from https://www.theguardian.com/us-news/2017/apr/10/united-airlines-videopassenger-removed-overbooked-flight

Lorenzetti, L. (2015). This is the most valuable bank in the world. Retrieved 10/18, 2017, from http://fortune.com/2015/07/23/wells-fargo-worlds-most-valuable-bank/

Maidenberg, M. (2017). United Airlines profit rises despite boycott threats over passenger treatment. Retrieved 10/20, 2017, from https://www.nytimes.com/2017/07/18/business/united-airlinesprofit-earnings.html

Marczyk, G., De Matteo, D., \& Festinger, D. (2005). In Kaufman A. S., Kaufman N. L. (Eds.), Essentials of research design and methodology Hoboken, N.J.: Wiley.

Massey, J. E. (2001). Managing organizational legitimacy: Communication strategies for organizations in crisis. Journal of Business Communication, 38(2), 153-182.

McCann, E. (2017). United's apologies: A timeline. Retrieved 10/20, 2017, from https://www.nytimes.com/2017/04/14/business/united-airlines-passenger-doctor.html

Meyer, J. W., \& Scott, W. R. (1983). Organizational environments: Ritual and rationality (Ex 02: 3. printing, 1985 ed.) Beverly Hills, Calif.: Sage.

Neate, R. (2015). Volkswagen under investigation over illegal software that masks emissions. Retrieved 10/16, 2017, from https://www.theguardian.com/business/2015/sep/18/epa-california-investigatevolkswagen-clean-air-violations

Patel, A., Su, T., \& Brooks, R. M. (2003). How the equity market responds to unanticipated events. The Journal of Business, 76(1), 109-133.

Piccoli, P., Chaudhury, M., Souza, A., \& Da Silva, W. V. (2017). Stock overreaction to extreme market events. North American Journal of Economics and Finance, 41, 97-111.

Pignataro, J. R. (2017). United Airlines controversy timeline: Full list of events after passenger dragged off plane. Retrieved 10/20, 2017, from http://www.ibtimes.com/united-airlines-controversytimeline-full-list-events-after-passenger-dragged-plane-2525027

Pignataro, J. R. (2017). United Airlines controversy: Read full CEO response to employees blaming plane passenger. Retrieved 10/20, 2017, from http://www.ibtimes.com/united-airlines-controversyread-full-ceo-response-employees-blaming-plane-passenger-2523787

Reckard, S. E. (2013). Wells Fargo's pressure-cooker sales culture comes at a cost. Retrieved 10/18, 2017, from http://www.latimes.com/business/la-fi-wells-fargo-sale-pressure-20131222-story.html

Reuters. (2017). Timeline: Volkswagen's long road to a U.S. dieselgate settlement. Retrieved 10/16, 2017, from https://www.reuters.com/article/us-volkswagen-emissions-timeline/timeline-volkswagenslong-road-to-a-u-s-dieselgate-settlement-idUSKBN14V100

Reuters. (2017). Timeline: Wells Fargo since sales scandal last year. Retrieved 10/18, 2017, from https://www.reuters.com/article/us-wells-fargo-accounts/timeline-wells-fargo-since-salesscandal-last-year-idUSKCN1BC5CW

Roberts, P. W., \& Dowling, G. R. (2002). Corporate reputation and sustained superior financial performance. Strategic Management Journal, 23(12), 1077-1093. 
Rushe, D. (2015). VW software scandal: Chief apologises for breaking public trust. Retrieved 10/16, 2017, from https://www.theguardian.com/business/2015/sep/20/vw-software-scandal-chiefapologises-for-breaking-public-trust

Rushe, D., \& Farrel, S. (2015). German minister tells Volkswagen to clear up emissions scandal. Retrieved 10/16, 2017, from https://www.theguardian.com/business/2015/sep/21/volkswagenshares-plunge-claims-falsified-emissions-data-us-epa

Stack, L. (2017). United Airlines offers refunds as outrage at a violent removal continues. Retrieved 10/20, 2017, from https://www.nytimes.com/2017/04/12/business/united-dragged-passengervideo-chicago.html

Suchman, M. (1995). Managing legitimacy: Strategic and institutional approaches. The Academy of Management Review, 20(3), 571.

United Airlines. (2017). Diversity and inclusion. Retrieved 10/20, 2017, from https://www.united.com/web/en-US/content/company/globalcitizenship/diversity.aspx

United Airlines. (2017). Eco-skies. Retrieved 10/20, 2017, from https://www.united.com/web/enUS/content/company/globalcitizenship/environment.aspx

United Airlines. (2017). Our shared purpose. Retrieved 10/20, 2017, from https://hub.united.com/sp/purposes/

Victor, D., \& Stevens, M. (2017). United Airlines passenger is dragged from an overbooked flight. Retrieved 10/20, 2017, from https://www.nytimes.com/2017/04/10/business/united-flightpassenger-dragged.html

Vineetha, D. S., \& Krishnakumar, K. (2015). Overreaction and underreaction in stock markets: A review. International Journal of Research in Business Management, 3(4)

Volkswagenag. (2017). Strategy 2025. Retrieved 10/16, 2017, from https://www.volkswagenag.com/en/group/strategy.html

Wattles, J. (2015). Volkswagen CEO sorry for 'broken trust'. Retrieved 10/16, 2017, from http://money.cnn.com/2015/09/20/autos/volkswagen-ceo-apology/index.html

Wells Fargo. (2016). Perspective on Sept. 8 settlement announcement. Retrieved 10/18, 2017, from https://stories.wf.com/perspective-todays-settlementannouncement/?cid=adv_prsrls_1609_102495

Wells Fargo. (2017). The vision and values of Wells Fargo. Retrieved 10/18, 2017, from https://www.wellsfargo.com/about/corporate/vision-and-values/

Yin, R. K. (2003). In Yin R. K. (Ed.), Case study research: Design and methods (3rd ed. ed.) Thousand Oaks, Calif: Sage. 